\title{
Modelling the Effects of Variable Tariffs on Domestic Electric Load Profiles by Use of Occupant Behavior Submodels
}

\author{
David Fischer, Student Member IEEE, Bruce Stephen, Senior Member IEEE, Alexander Flunk, Niklas \\ Kreifels, Karen Byskov Lindberg, Member IEEE, Bernhard Wille-Haussmann, Edward H. Owens
}

\begin{abstract}
Emerging infrastructure for residential meter communication and data processing carries the potential to control household electrical demand within local power system constraints. Deferral of load control can be incentivised through electricity tariff price structure which can in turn reshape a daily load profile. This paper presents a stochastic bottom-up model designed to predict the change in domestic electricity profile invoked by consumer reaction to electricity unit price, with submodels comprising user behaviour, price response and dependency between behaviour and electric demand. The developed models are used to analyse the demand side management potential of the most relevant energy consuming activities through a simulated German household demonstrating that in the given scenario $8 \%$ of the annual electricity demand is shifted, leading to a $35 €$ annual saving. However, a $7 \%$ higher than average peak load results from the structure of the tariff signal modelled herein. A discussion on selected aspects for tariff design for categories of typical household appliances is included.
\end{abstract}

Keywords: Demand Side Management, Electric Load Profile, Stochastic Occupancy Bottom-up Model, Elasticity, Behaviour Change, Load Modelling, Variable Electricity Price

\section{INTRODUCTION}

The share of renewables in electricity generation portfolios across the EU is growing steadily with a resulting increase in intermittent generation capacity leading to a paradigm shift towards flexible demand in power system operation. To maximise the utilization of renewable electricity generation, Demand Side Management (DSM) [1] targets shifting of electrical demand to reshape load profiles in accordance with available generation. This may be achieved by starting and stopping certain energy consuming appliances for example.

In [2], different approaches to DSM and the variety of DSM options, stakeholders and possible targets for DSM in different sectors were highlighted. Traditionally DSM has been the preserve of large industrial customers, mostly with a focus on peak load reduction to avoid capacity charges [3],

David Fischer, Alexander Flunk, Niklas Kreifels and Bernhard WilleHaussmann are with the Department of Electrical Energy Systems, Fraunhofer Institute for Solar Energy Systems, Freiburg, Germany e-mail: David.Fischer@ise.fraunhofer.de.

Karen Byskov Lindberg is with the Department of Electric Power Engineering, Norwegian University of Science and Technology NTNU, Trondheim, Norway.

Bruce Stephen is a Senior Research Fellow in the Advanced Electrical Systems Research Group, Institute of Energy and Environment, University of Strathclyde, Glasgow, Scotland

Edward H. Owens is Senior Lecturer at the school of the Built Environment Heriot-Watt University Edinburgh, Scotland
[4]. However through the availability of inexpensive communication, computation and actuation technology, DSM opportunities in the residential and commercial sectors are also expected to be included [5], [6]. A challenge in the field of DSM in the residential sector is the modelling and prediction of changes in load profile resulting from changes in energy consumption habits, induced by a varying electricity price during the day. In the presented work, consumer reaction to price change is modelled on a response rate which adds a new method to the modelling portfolio for user behaviour. In contrast to many approaches, based on the automated control of devices for DSM [7]-[9], this work highlights the potential of achieving a load shift without the need for extensive additional technology to be applied in the field. Thus the benefits of DSM technology can be analysed and related to the findings of this study and in doing so will help improve classic elasticity based models consequently contributing to an improved understanding of the driving factors of load profile changes and therefore informing the design of future variable tariffs.

\section{A. Energy Consumption and DSM in Households}

Electricity demand in households is created by the utilisation of electric appliances, which can be categorized in terms of flexibility and controllability [10]. For example, lighting can be controlled easily but may not be flexible in its time of use and thus offers little opportunity for DSM. In contrast some wet appliances may be turned on and off at random without the residents experiencing any significant disadvantage to their lifestyles. The proportional contribution of appliances to overall domestic energy consumption is displayed in Table I] Appliances under direct user control account for about $68 \%$ of household electricity consumption, while appliances that are usually installed, configured, and then operated autonomously, are classified as being under indirect user control and account for $32 \%$ of the household electricity demand.

Two main approaches to demand side management in households have been employed in previous works:

1) Forced control of appliances by actuation technology e.g. by using smart plugs [12] or more advanced control systems [13]

2) Change of customer's consumption behaviour through financial incentives and provision of information to enable informed energy use scheduling.

In the first approach automated appliances like heat pumps [14], hot water tanks [15], fridges or finite state appliances 
TABLE I

SHARE OF DOMESTIC ELECTRICITY DEMAND BY APPLIANCE.

\begin{tabular}{lr}
\hline Appliance & $\begin{array}{r}\text { Electricity demand } \\
\text { share }\end{array}$ \\
& {$[\%]$} \\
\hline Under direct user control: & $\mathbf{6 8 \%}$ \\
\hline Office Equipment & 14.5 \\
Entertainment & 13.3 \\
Laundry ${ }^{1}$ & 13.1 \\
Lighting & 11.1 \\
Cooking & 10.1 \\
Dish washing & 5.9 \\
\hline Under indirect user control: & $\mathbf{3 2 \%}$ \\
\hline Fridge & 12.0 \\
Pumps & 7.4 \\
Freezer & 5.3 \\
Other & 7.4 \\
\hline Includes drying & ${ }^{2}$ Source: $[11$; Percentage sectoral demand without electrical \\
& domestic hot water
\end{tabular}

such as dish-washers, washing machines or tumble driers, are equipped with controllers for DSM [7]-[9]. A change of start and end times as well as an interruption of operation is achieved via a local or centralised controller, which could be placed at the utility [5], to manipulate the premises' load profile. The drawback of using automated actuation devices for DSM are the costs of installation and the risk of lack of acceptance of automated devices in private homes [16]. If actuated systems are not within the range of available options, financial incentives and educational measures targeted to influence the occupants' energy consumption behaviour are an alternative [17], [18].

In an analysis of the benefits and drawbacks of DSM, [16] pointed out that a lack of information technology and communication infrastructure, increased costs and complexity, as well as inappropriate market structures can be among the main obstacles to DSM programmes. The models and results presented in this work enable the potential of a lowtech, low cost and low complexity approach to DSM, which is achieved by solely relying on user response to a pricing structure comprised of variable tariffs.

\section{B. Electricity Prices and Structure}

Financial incentives that target change in the energy consumption patterns of households can be applied in the form of variable tariffs. The structure can differ in the value, number of price steps and the timing of high and low prices during the day. At one extreme of complexity electricity prices can be changed irregularly throughout the day or simply consist of a simple two-stepped price signal, contrary to the flat price model commonly used for German residential customers. In selected field studies taking place in Germany, different tariff structures with two to five prices during the day, have been tested [19]-[21].

The nature of the tariff structure depends on the intended effects on the electric load profile, which could be:

- Maximum utilization of renewable energy

- Peak shaving

- Low cost energy purchase

Using automated actuation devices, that are able to calculate an optimal operation strategy based on a given price signal, places no limitations to the tariff structure and its
TABLE II

ELECTRICITY PRICE RATIOS OF SELECTED GERMAN DSM STUDIES.

\begin{tabular}{llll}
\hline Study & $\begin{array}{l}\text { Low price } \\
\text { ct/kWh }\end{array}$ & $\begin{array}{l}\text { High price } \\
\text { ct/kWh }\end{array}$ & $\begin{array}{l}\text { High/Low } \\
\text { Ratio }\end{array}$ \\
\hline E-DeMa [19] & 8.49 & 21.69 & 2.55 \\
eTelligence [21] & 11.67 & 39.79 & 3.41 \\
Intellikon [20] & 15.50 & 27.40 & 1.76 \\
MoMa [22] & 15.00 & 25.00 & 1.67 \\
\hline
\end{tabular}

intraday variability apply. However when working directly with the householder, there is a limitation on task complexity imposed by human capabilities of calculating an optimal operational strategy. This assumption is also supported by the E-DeMa study [19], explained in more detail in Section II-B, where the participants could choose between four different tariff structures which were: fixed price, two-stepped, four-stepped and five-stepped. In this example $87 \%$ of the customers selected the two-stepped price signal, 5\% selected the four-stepped and $8 \%$ the five-stepped signal. This leads to the conclusion that complex tariff structures are unlikely to be accepted and reacted upon by the consumer. For this reason a two stepped price signal is introduced in Section II-C and used for the investigations of a change in load profiles presented in Section III

When discussing tariff structures the number of steps and also the difference in price between steps have to be considered. To illustrate this point price ratios of selected German DSM projects are listed in Table II

\section{Predicting User Response to a Price Signal}

Modelling the cause and effect of modified electricity consumption by load shifting in households through changing occupants behaviour is still a challenge. Relying on customer effort to adapt energy to suit DSM requirements, leads to the question of how to predict the change of energy consumption during the day and over longer time frames, in response to the tariff structure. A widely used modelling approach for this is based on the price elasticity of demand [23], which is rooted in the field of economics. A main challenge of the elasticity based approaches is the definition of elasticities and cross-elasticities, which determine the absolute power change and its shift over time. The presented work shows an approach to overcome some of the difficulties with crosselasticity, but can still be easily combined with general price-elasticity models. A core concept of the presented approach is that energy consumption habits are distinct and depend on personal needs and the purpose of the energy use. While a large part of human activity, sleeping and eating for instance, is unlikely to be changed due to external incentives, there exists a set of activities which can be shifted without considerable inconvenience or loss of quality of life. This assumption is supported by the E-DeMa study [19], which shows that different activities are not equally likely to change under a variable price scheme. Practice theory is used in [24], [25] to conceptualize and explain energy consumption behaviours, routines and possible flexibility. While formalisms are emerging [26] , a model that quantifies demand changes in reaction to pricing signals has yet to emerge as a standard approach. 
In [27 elasticity theory is applied to electric demand under real time prices; [28] extends this approach including a non-linear elasticity function and a classification of customers' flexibility and its impact on the structure of the cross-elasticity matrix, which accounts for the impact of a price change at one point in time upon electricity demand at other points in time. The approaches in [27]-[29] focus on the resulting change in load with no indicator of the underlying processes that constitute it, while in [30], [31], elasticity is applied to starting probabilities of electric appliances. In this work a simple, straight forward method, which takes into account user preferences for the use of the appliance and the responsiveness for each activity towards a price change is presented which can enrich or substitute existing elasticity based approaches. Although inflexible personal routines as highlighted in [26] are not explicitly captured, the presented methods implicitly build on daily routines and a load shift will occur in line with observed temporal preferences for each activity.

\section{Modelling Household Electric LoAd Profiles UNDER VARIABLE TARIFFS}

Domestic electricity demand is classified into consumption caused by appliances under direct user control and under indirect user control (see Section $[-\mathrm{A}$ ). The effects of modified user behaviour on the use of directly controlled appliances are modelled using three submodels:

1) A model for user behaviour under "normal" conditions (submodel 1).

2) A model for how behaviour changes i.e. how the user responds to a given price signal (submodel 2).

3) A model for mapping user behaviour to energy consumption (submodel 3).

The combination of these three submodels leads to the model proposed in the following sections.

\section{A. Main Model}

The electrical load model is based on the stochastic bottom-up approach presented and validated against 430 households in [32]. For each activity, information on frequency, start time and duration are provided in the form of the probability distributions shown in Figure 4. The response to a price signal is modelled by modifying the probabilities of the start times for each appliance within the constraints of the following assumptions:

- 24 hours in advance of any given day, the user is provided with the price signal for that day.

- The user performs a certain activity, such as watching TV or cooking, n-times during a day. The number of starts of each activity is kept constant since the need to undertake an activity is assumed to be independent of its timing.

- Willingness to react to the signal, referred to as response rate, is different for each activity according to the importance of the activity to the user.

- Once started, an activity will take as much time as it normally does when started at this time of the day.

Figure 1 shows the inputs, main calculation steps and outputs of the behavioural model. The case characterised by a constant electricity price is referred to as business as usual (BAU).

Inputs: household appliance stock is provided to the model and taken from [11], [33]. Statistics of BAU user behaviour is retrieved from the Harmonized European Time of Use Survey [33] and included as a probability distribution.

Calculation Steps: The changed start time probability is calculated as a weighted mix of the original distribution and a distribution resulting from a complete adjustment of behaviour towards the price signal. For each appliance the probability of use is established using submodel 1 for the BAU case. This probability distribution is changed according to the price structure and the expected user response presented in Section $\llbracket-B$. In submodel 2 the probability of use when responding $100 \%$ to a given price signal is calculated for each appliance and used together with the expected response to calculate the changed probability distributions.

Outputs: Submodel 3 maps electrical demand to each activity using measured load traces and calculates an aggregated load profile for a household.

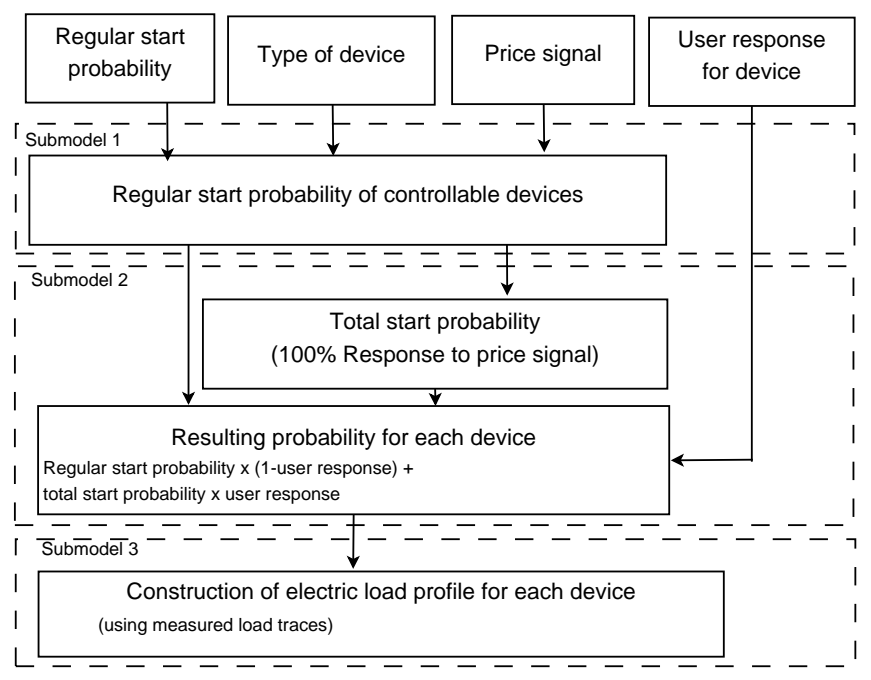

Fig. 1. Inputs, main calculation steps and outputs of the behavioural model.

\section{B. Data used}

In 2012 an 2013 the E-DeMa study [19], financed by the German government, investigated the potential of intelligent energy control systems and modified user behaviour in Germany. As a part of that study 575 electricity customers were equipped with smart meters and given the opportunity to select between different tariff schemes. After the project an a-posteriori interview was performed, asking whether and how often the participants changed a certain activity in response to the tariff with the findings compared to measured electricity consumption data. One of the findings was that users responded differently depending on which activity was being modified. Figure 5 shows an example of the possible answers and their distribution on the question, 'How often did you change activity X?'. The data extracted from over 350 questionnaires is used to calibrate the behavioural model described in the following section. 


\section{Electricity Tariff Structure}

Motivated by the observations that customers prefer a tariff structure with low complexity, as explained in section I-B. a two-stepped tariff structure (high-price and low-price), was chosen to be implemented in the model as a binary signal. This signal $s$ is used for dividing the day into timeslots $t$ where consumption is preferred or discouraged according to the price $p$ :

$$
s(t)= \begin{cases}1 \Leftrightarrow & p(t)=\text { Low } \\ 0 \Leftrightarrow & p(t)=\text { High }\end{cases}
$$

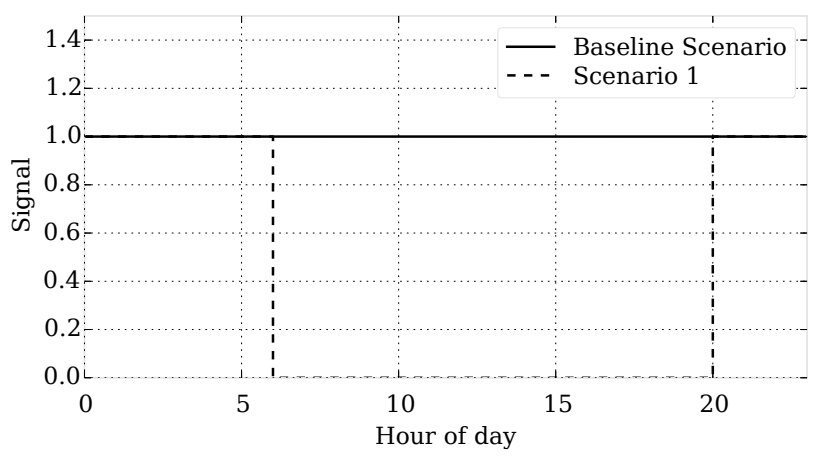

Fig. 2. Price signal $s(t)$ sent to the consumer in scenario 1 according to scenario 1 ( 0 - high price / 1 - low price).

The signal indicates favourable times to use an appliance (at low price level, $s=1$ ) and when to avoid energy consumption (at high price level, $s=0$ ). The tariff structure chosen for scenario 1 is taken from [19] and strives to reduce load during daytime hours. In this study the price ratio of high to low was 2.55, the prescribed hours of high and low prices are shown in Figure 2 and compared to a baseline scenario characterised by a constant electricity price.

\section{Submodel 1: Modelling User Behaviour}

User behaviour is modelled using a stochastic bottomup approach based on time of use survey (TUS) data [33]. For each household appliance a usage schedule is generated for each day using the procedure described in Figure 3 The devices are separated into two classes: those that are activity independent, such as fridges and routers, and those that have a dependence on domestic activities, such as TVs or wet appliances.

The number of starts, the start time and the duration for each activity, is sampled from probability distributions derived from the time of use data. An important feature of this model is that the duration of use is linked to the start time.

Seasonal effects, such as reduced TV viewing hours during summer month, are accounted by adjusting the number of starts during the course of the year. The probability distributions for the number of starts are adjusted according to the analysed data. Further seasonal effects are included in the lighting model. The electricity consumption for electric lighting is dependent on the global irradiation outside the building and the number of persons present in the dwelling.
It is possible that a single type of appliance could be used by more than one person at the same time. This is accounted for with a co-use factor, which is derived from the TUS data [33] and is dependent on the activity type and the number of persons living in the same dwelling. The starting probability is reduced according to the co-use factor to account for shared appliance use.

One central modelling assumption is that all appliances can be used independently of each other and thus could be used simultaneously. While this may hold for some appliances it was shown in [26] that certain activities share a defined set of patterns. To account for this, a class of finite state appliances/activities are incorporated into the model. The appliances used for these activities are used in a predefined sequence and additionally follow a discrete program (for example laundry machines). Thereby the use of one appliance is linked to the prior use of another appliance for laundry and kitchen devices. For all cooking activities one sequence reflects the preparation of a certain type of meal. The use of a tumble dryer after the use of a washing machine and the time in between are randomly selected. Clearly, exploring more detailed forms of this relationship is an area of further research in its own right [34].

Validation of the model has been conducted with 430 measured electric load profiles using Pearson's correlation coefficients for the average daily load profile varying between 0.85 and 0.97 depending upon the day of the week and the group considered. The validation methodology is given a full treatment in [32], but MAPE values obtained vary between $6.1 \%$ to $16 \%$., which is comparable to measurement based forecasts for residential premises [35].

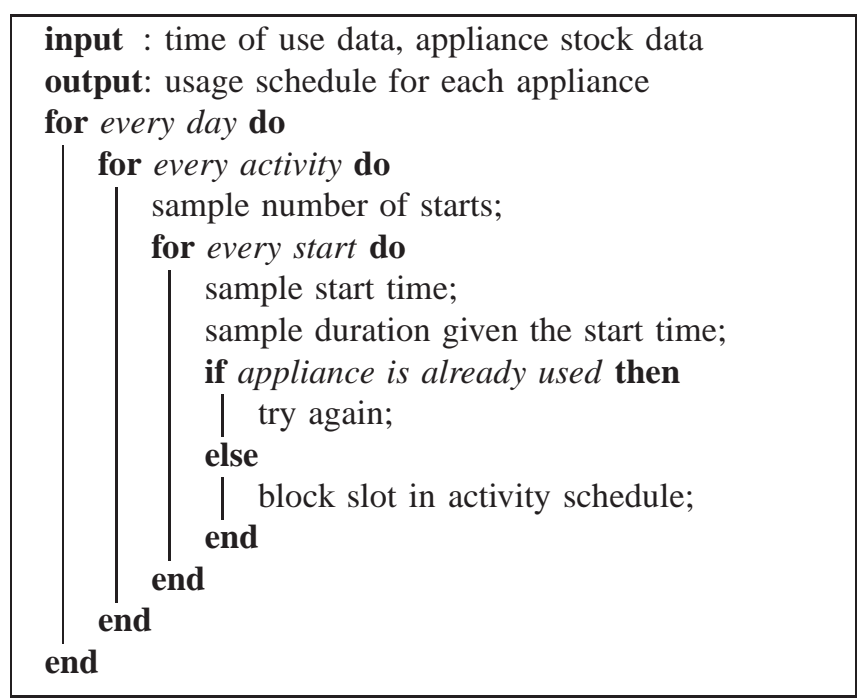

Fig. 3. Routine for generating an activity schedule for all appliances.

\section{E. Submodel 2: The Change in User Behaviour}

To model alterations in user behaviour, users are divided into two extreme categories: a BAU user whose behaviour remains unchanged and a responding user who always reacts $100 \%$ to the price signal. The changed user behaviour is a mix of both probability distributions according to the response rate. The weighting of the probability distributions is set according to the reported response rates. The modified 

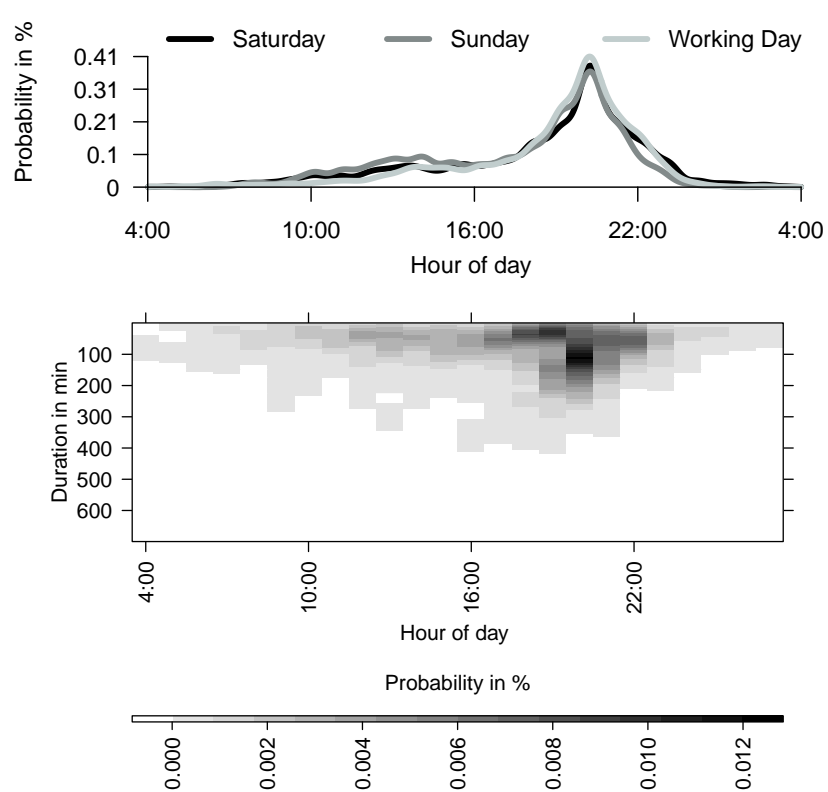

Fig. 4. Probability distribution of starting to watch TV at each hour of the day (top) and the joint probability distribution of the duration watching TV conditional on the start time on saturdays (bottom). Both for business as usual (BAU) case.

TABLE III

PROBABILITY OF USER RESPONSE DERIVED FROM THE QUESTIONNAIRE.

\begin{tabular}{ll}
\hline Answer & Mapped response probability \\
$a$ & $M_{\text {Resp }}$ in $\%$ \\
\hline Always & 100 \\
Often & 75 \\
Occasionally & 50 \\
Rarely & 25 \\
Never & 0 \\
\hline
\end{tabular}

distributions still incorporate users timely preferences for certain activities. As a result the time to which an activity is shifted is still in line with the user's preferences of when to undertake that particular activity

When responding to the signal, the user is expected to shift the start of certain activities with a likelihood of reacting to the signal referred to as the user response rate which depends on the type of activity and its importance to the user. Figure 5 shows a set of answers $a$ reflecting the willingness to change an activity as reported in [19]. The answers are mapped into probabilities for user response $M_{\text {Resp }}(a)$ according to their counts $w$ in the interviews and using Table III For each activity $X$ the expected value $E_{\text {Resp }}$ for an user responding to the price signal is calculated according to:

$$
E_{\text {Resp }}(X)=\frac{1}{\sum_{a=1}^{n} w_{\text {Resp }}(a)} \cdot \sum_{a=1}^{n} M_{\text {Resp }}(a) \cdot w_{\text {Resp }}(a)
$$

Highlighted in Figure 6 are the differences in expected response: dish-washing and laundry exhibit about three to four times higher response rates than the other activities considered. Response affects start time and this is accommodated with a new start time probability distribution consisting of three parts:

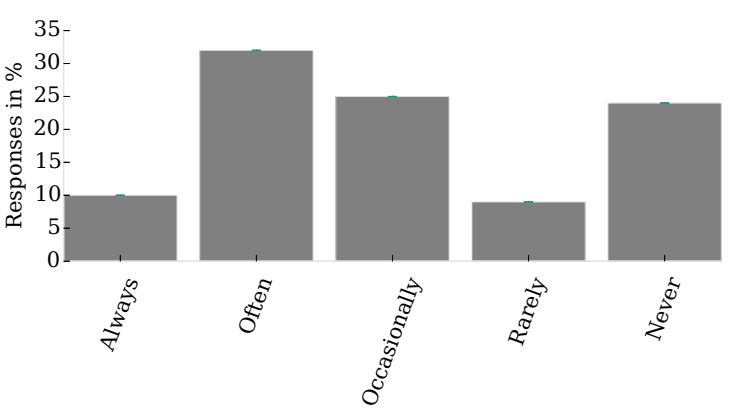

Fig. 5. Response to the signal of the participating users. Answer to the question 'How often did you change laundry times according to the price?' $(\mathrm{N}=404)$. 19

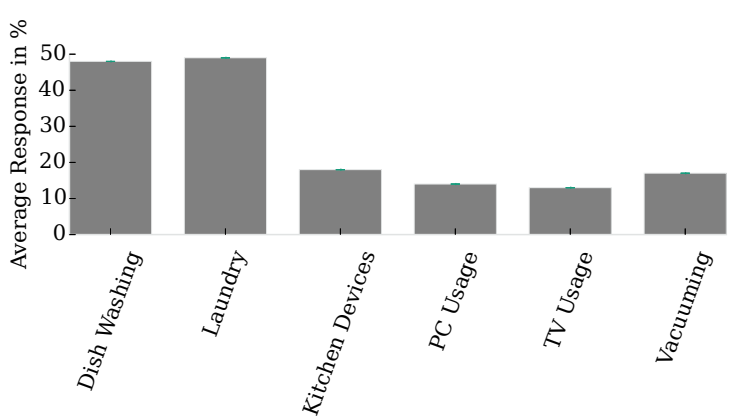

Fig. 6. Expected response $E_{\text {Resp }}$ for the activities considered in the behavioural model $(\mathrm{N}=359-404)$. [19]

1) The business as usual (BAU) user: In this case there is no response to the signal and the start time distribution is unchanged as described in Section $\amalg-\mathrm{D}$.

2) The responding user: The other extreme is the responding user who reacts $100 \%$ to the signal: all activities are shifted to favourable timeslots and unfavourable timeslots are avoided. For the responding user the probability $P_{\text {Resp }}(X, t)$ of starting an activity $X$ at a certain time slot $t$ is derived by multiplying the probability of the BAU user $P_{\mathrm{BAU}}$ with the price signal $s(t)$ described in Sec $\amalg-\mathrm{C}$.

$$
\begin{gathered}
P_{\text {Resp }}(X, t)=P_{\mathrm{BAU}}(X, t) \cdot s(t) \\
\forall s(t) \in\{0,1\}
\end{gathered}
$$

The resulting daily probability distribution is normalized. This distribution still reflects user preference of when to undertake an activity but completely avoids start times in high price time slots.

3) Merging - The changed user: One interpretation of the questionnaire results shown in Figure 6 is that a response rate of $x \%$ is equivalent to showing a $100 \%$ responding behaviour on $x \%$ of the days. This interpretation is used to calculate the changed probability distribution of start times. To derive the changed start time probability distribution $P_{\text {New }}(X, t)$ for each activity $X$, the distributions of the BAU user and the responding user are weighted according to the expected response $E_{\text {Resp }}(X)$ as calculated in eq. 2 and summed:

$$
\begin{aligned}
P_{\text {New }}(X, t) & =E_{\text {Resp }}(X) \cdot P_{\text {Resp }}(X, t) \\
& +\left(1-E_{\text {Resp }}(X)\right) \cdot P_{\mathrm{BAU}}(X, t)
\end{aligned}
$$




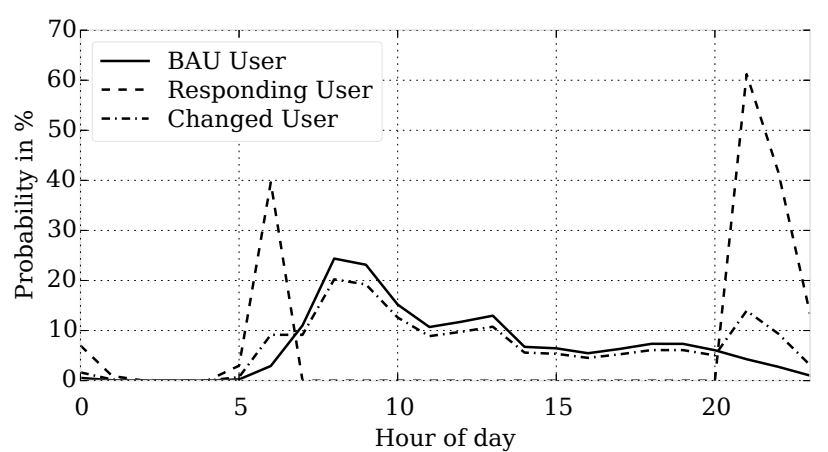

Fig. 7. Expected probability distribution for vacuuming for the different user types.

Figure 7 shows the start time probabilities for the different user types when the price signal described in Section $\amalg-C$ is applied.

\section{F. Submodel 3: Mapping Behaviour to a Load Profile}

With the use of submodel 1 and 2, a schedule for the considered activities $X$ for each timeslot in the day $t$ is derived according to whether an activity $i$ is either performed $\left(X_{i}(t)=1\right)$ or not $\left(X_{i}(t)=0\right)$. For each activity the corresponding electric appliance is used. Based on measured data a load trace $P_{\mathrm{el}, i}$ for each appliance $i$ is generated, depending on the duration of use.

$$
\begin{array}{r}
P_{\mathrm{el}}(t)=\sum_{i=0}^{n \_a} X_{i}(t) \cdot P_{\mathrm{el}, i} \\
\forall X_{i}\{0,1 \in\}
\end{array}
$$

Load traces can then be aggregated together to form a household load profile as in [32].

\section{DSM Potential FOR German Single Family HOUSES}

A one year simulation using 500 single family houses with 3 occupants was undertaken to investigate the electric household load profile under different tariff structures. The age and work pattern of the occupants and the appliance portfolio of each building were sampled from a representative distribution for Germany [33]. Each household was simulated on a 10 second base and the results were averaged to a one hour time step. Regular public holidays are included. Simulations were performed for the signal introduced in Section $\amalg-\mathrm{C}$ which in turn produced a reported user response, introduced in Section $\amalg-\mathrm{E}$, used to calculate the modified activity schedule for one day. To examine the effects of different tariff structures, two additional simulation runs were completed with one structure that was used in the Intelliekon study [20] and one designed to reduce load peaks. The aim of the following investigation is to evaluate of the effects of the two-stepped price signal on the shape of the daily electric load profiles. Further, the potential for DSM actions by use of individual electric appliances is evaluated.

\section{A. Change of the Daily Load Profile}

In Figure 8 he daily electric load profile under normal conditions (i.e. a constant price) is compared to the load profile when applying a two-stepped tariff (scenario 1). Under normal conditions the electric load profile shows two characteristic peaks - the first peak occurs at around $12 \mathrm{am}$ with a second considerably higher peak occurring around $7-8 \mathrm{pm}$. In the morning a steady rise in electricity demand is observed beginning after the fourth hour of the day. The changed load profile, when users responded to the price signal, shows a different characteristic: the two peaks at 12 and around $7 \mathrm{pm}$ persist but are now less distinct. Generally, energy consumption during high price hours is reduced. During the night time period (12:30 a.m. - 4:30 a.m.) energy consumption in both cases is almost identical. Moving activities out of the expensive hours of the day into low price periods, leads to two new peaks in the load profile: a first peak in the early morning and a second peak, even higher than the one before applying the signal, in late evening. In the morning hours, the changed profile shows a higher demand in hours of high price periods than in the baseline scenario, which can be attributed to an appliance being started in a low price period but continuing to operate through to a high price period.

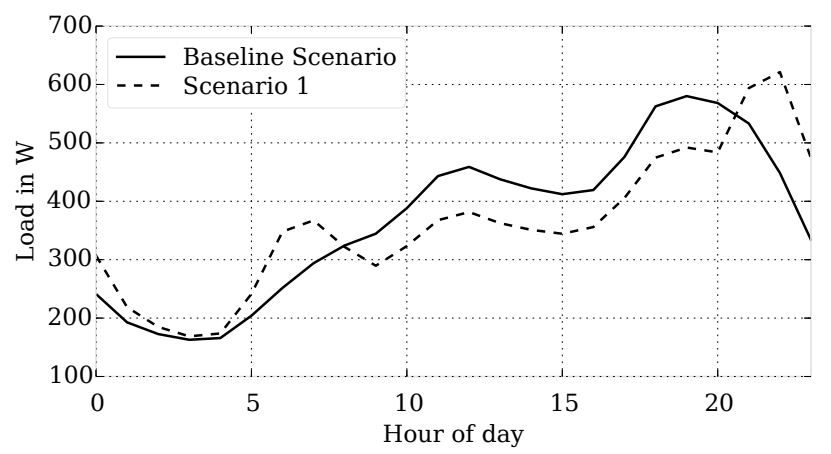

Fig. 8. Average electrical load of a household, under BAU conditions in the baseline scenario and with the influence of the signal in scenario 1 .

\section{B. Annual Comparison of the Load Profiles}

A comparison of the annual duration curves for the cases investigated is shown in Figure 9, annual energy consumption is $3197 \mathrm{kWh}$ per annum in scenario 1 and about $1 \%$ higher in the baseline scenario. This effect is a result of the fact that activities such as watching TV, when started late in the evening, are used for a shorter duration than when started earlier in the evening in the BAU case. The shape of the annual duration curve is flattened as a consequence of the price signal, whereas the annual peak is increased by $9 \%$.

\section{Contribution of the Individual Technologies to Load Shifting}

To investigate the contribution of each technology to load shifting, the daily shifted energy for each appliance is listed in Table IV. On a daily basis on average $729 \mathrm{Wh}$ were shifted, equal to $8 \%$ of the total daily electricity consumption which 


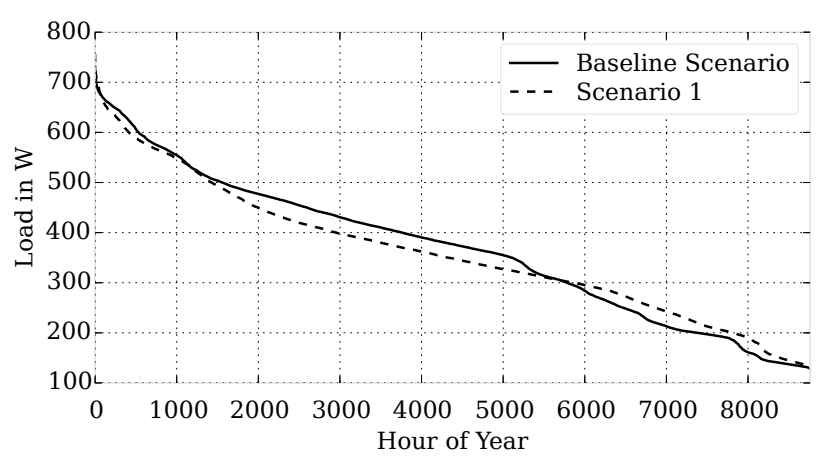

Fig. 9. Annual duration curve for the baseline scenario compared to scenario 1.

leads to an annual saving of $35.1 € /$ a, given a low/high price of 8.49 and $21.69 € \mathrm{ct} / \mathrm{kWh}$. The highest contribution in terms of shifted energy was achieved by changed laundry, followed by dish-washing and cooking which lead to savings of $16.4 € / \mathrm{a}, 8.4 € / \mathrm{a}$ and $4 € / \mathrm{a}$ respectively. The share of shifted energy to the total demand of each appliance shows that about $31 \%$ of the electricity consumption for laundry and dish washing was shifted to favourable hours. Cooking, PC-use, cleaning and ironing were shifted by between $6 \%$ and $10 \%$ and shifting of TV related consumption was $2 \%$.

TABLE IV

SHARE OF TOTAL ELECTRICITY CONSUMPTION, SHIFTED ENERGY AND RESULTING SAVINGS FOR THE INVESTIGATED SCENARIO.

\begin{tabular}{lllll}
\hline & $\begin{array}{l}\text { Share of } \\
\text { total } \\
\text { Demand } \\
\text { \% }\end{array}$ & $\begin{array}{l}\text { Shifted } \\
\text { Energy }\end{array}$ & $\begin{array}{l}\text { Shifted } \\
\text { Energy }\end{array}$ & Savings \\
Categories & Wh/d & \% & €/a \\
\hline Laundry & $12 \%$ & 340 & $31 \%$ & 16.4 \\
Dish washing & $6 \%$ & 175 & $31 \%$ & 8.4 \\
Cooking & $10 \%$ & 86 & $10 \%$ & 4.1 \\
PC & $13 \%$ & 72 & $6 \%$ & 3.5 \\
TV & $11 \%$ & 23 & $2 \%$ & 1.1 \\
Cleaning dry & $2 \%$ & 21 & $10 \%$ & 1.0 \\
Ironing & $1 \%$ & 13 & $12 \%$ & 0.6 \\
\hline Total & $55 \%$ & 729 & $8 \%$ & 35.1 \\
\hline
\end{tabular}

\section{Effect of Signal Shape on the Load Profile}

As described in Section $\amalg$ II-A an increase in the number and value of the load peaks during the day is observed when applying the two-stepped signal given in II-C. To investigate the effect of different tariff structures, two further scenarios were simulated and the results can be seen in Figure 10 The first additional signal (scenario 2) is a two stepped signal equal to the one used in the Intelliekon study, which investigated DSM in private households [20]. In this case the high time is set from 11 a.m.- 5 p.m.. The second additional signal (scenario 3 ) is a peak-shaving signal, which is derived from the household load curve of the baseline scenario. During times of high load from 10 a.m. to 2 p.m. and 4 p.m. to 9 p.m. a high price is applied. At times of typically low electricity demand, a low electricity price was applied to motivate a shift of energy consumption to these hours. The high to low price ratio was kept constant for all cases. Using the Intelliekon tariff structure, the morning peak is shifted to earlier hours and the evening peak is delayed by one hour with the evening peak higher than in the baseline scenario. The signal which was intended to reduce the load peaks actually leads to a flattening of the evening peak with a higher demand in the late afternoon; the morning peak is only slightly higher than in the baseline scenario though.
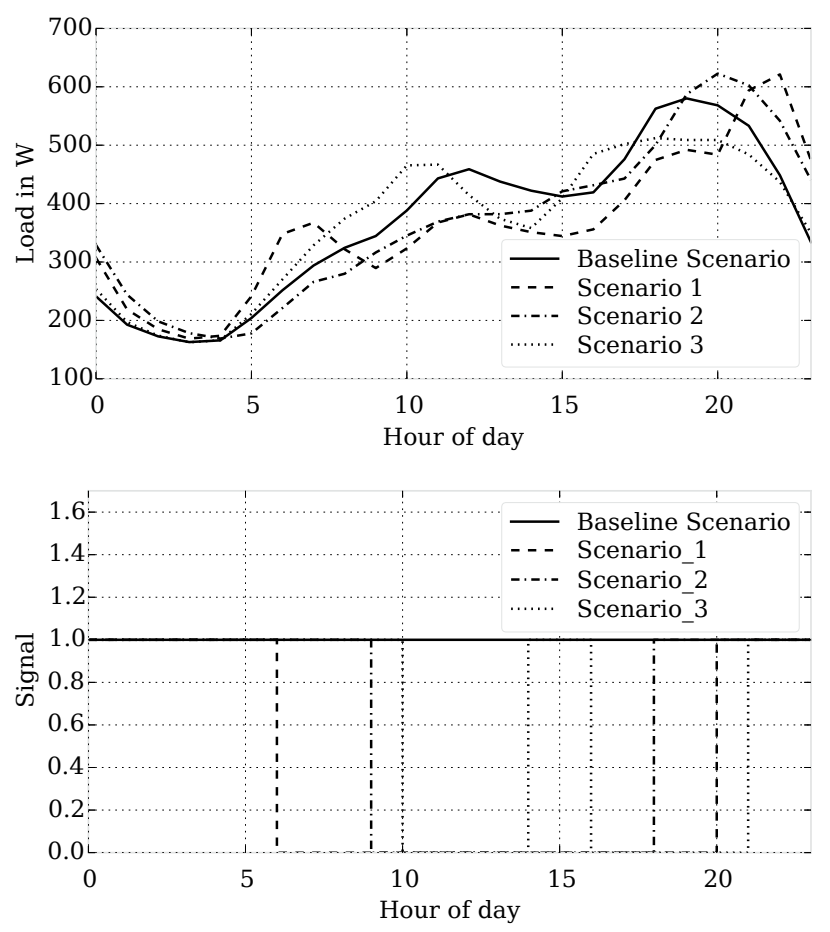

Fig. 10. Influence of different price signals $(0$ - high price / 1 - low price $)$ on the average daily load profile (top)

\section{Discussion OF Results}

Results in Figure 10 show that the price signal shape has a strong influence on the load profile. In all cases a variation in the tariff structure leads to reduced consumption in high price hours with an increased consumption at hours where price is low. For all tariff structures an increase in consumption can be observed at hours where the electricity price changes from high to low, however, if these high to low price shifts occur during the early evening, new and higher load peaks than in a constant price scenario are exhibited, an effect which should be taken into account when designing tariff structures for different customer groups. Observation of new peaks is consistent with the statements in [16], where the effect of disturbed natural load diversity by DSM is discussed. Similar observations for automated devices are described as rebound effects in [36], reported as an increase of load leading to a new peak when interrupted processes try to catch up after blocking times are passed.

Results in Table IV] show that about $8 \%$ of the total demand was shifted, which corresponds well with the results of the active participants in the E-DeMa study who shifted $8.6 \%$ of their energy consumption against an average shift of $3.6 \%$ for all study participants. The small discrepancy may be attributed to an overly optimistic self-evaluation regarding the change of behaviour as well as the assumption 
of conditional independence of activities this allows for a theoretical simultaneous shift of all activities towards favourable points in time, which might not be realisable for activities that are inherently coupled. The value for load shifting calculated in this work is clearly below the $32 \%$ that has been estimated by [10], but close to the $12 \%$ which is observed in the field trials reported in the same study.

The current modelling approach assumes that most of the appliances are independent (see section II-D) which has an effect on the results which may, in a rare case, lead to a simulation timeslot where the maximum possible number of appliances are operated simultaneously. Although the majority of appliances could theoretically be operated at the same time, this is constrained by an individuals' multitasking capability. Whereas semi-automated appliances such as dish-washers and laundry machines as well as base-load devices do not face a limitation in simultaneity, appliances requiring user interaction are limited in this manner. Table IV shows that cooking, the use of PCs and TVs, vacuumcleaning and ironing account for $17 \%$ of the daily shifted energy, which implies that simultaneous operation of those appliances, based on the assumption of mostly independent appliances, could lead to an overestimation of the new load peaks that may result. In households with a low number of occupants and thus a high number of appliances per dweller overestimation is most severe. However for the investigated case with three persons per household this effect is reduced. In aggregation over many households, over the year and with increasing number of dwellers in the living unit the resulting peak will be further smoothed.

Whereas possible peak over estimation is a weakness of the presented approach the quantification of shifted energy remains unaffected by the partial independence assumption. The response rate to a price signal used in section II-E to determine the new starting points already accounts for inconveniences occurring and limitations in multi-tasking of a single dweller. A combination of the presented approach with practice theory could further improve the results by better representing peoples routines and avoiding too many things being done at the same time.

Regarding the financial benefits resulting from a shift of energy, for scenario 1 savings of $35.1 € /$ a have been achieved for a three person household. It is apparent from Table IV that laundry and dish washing contribute most to the benefits of a variable tariff structure. While the model used here assumes an occupant starts the appliance, wet appliances can generally be equipped with a timer or some form of automated controller, which will increase the viability of DSM. In contrast, cooking, PC-use, watching TV as well as cleaning and ironing seem to offer little potential for shifting, which may be due to the fact that those appliances are commonly not used at hours when a high price was applied, or that the user response and thus the willingness to adapt is considerably lower for those activities (see Figure 6). About $10 \%$ of the electricity consumption for ironing and cleaning was shifted, which indicates a general potential for flexibility of those appliances, but since their share of the total electricity consumption is only $3 \%$, the impact is almost negligible.

\section{CONCLUSION}

Correctly anticipating the expected change in individual households load profiles is particularly valuable in the design of electricity tariffs. This paper has proposed a model to predict the change of the electricity load profile in response to the application of a variable tariff structure, showing accurate prediction of shifted load under particular cases. In the scenarios investigated, around $8 \%$ of the total domestic demand was shifted, which corresponds well with previous trial results and results in a financial gain of $€ 35 /$ year. Over $50 \%$ of this saving came from wet appliance usage with an almost trivial contribution of $€ 5 /$ year coming from shifting consumer electronics and TVs, highlighting their lack of usefulness in demand response.

Load shifting comes with a consequence though, as it was shown that additional peaks in the load profile can occur which are even higher than the peaks present without the application of a variable tariff structure. This work has highlighted the importance human factors play in DSM: different household types show different consumption patterns and thus an individual availability of DSM capacity during the day. In the same vein, the expected motivation to respond to a variable price is highly dependent on the following three human oriented factors:

1) The importance of the activity

2) The value to the user of responding to the tariffs and their inherent elasticity

3) The time of day when a specific change of behaviour is demanded from the user

Lastly, tariff complexity must remain within limits of the understanding of the consumers as overly fine grained tariff structures will be burdensome to follow consistently. Building on the model developed here, it will be possible to design customer specific tariff schemes based on predicted household specific changes in load profile.

\section{ACKNOWLEDGMENT}

The research leading to these results has been conducted within the ORIGIN Project and has received funding from the European Union Seventh Framework Programme (FP7/2007-2013) under grant agreement $N^{\circ} 314742$.

\section{REFERENCES}

[1] V. Vittal, "The Impact of Renewable Resources on the Performance and Reliability of the Electric Grid," The Bridge, vol. 40, no. 1, pp. 1-4, 2010. [Online]. Available: http://texasinstitute.typepad.com/files/ the-bridge-spring-2010-edition.pdf\#page $=7$

[2] R. Delgado, "Demand-side management alternatives," Proceedings of the IEEE, vol. 73, no. 10, pp. 1471-1488, 1985. [Online]. Available: http://ieeexplore.ieee.org/lpdocs/epic03/wrapper. htm?arnumber $=1457587$

[3] S. Ashok and R. Banerjee, "Load-management applications for the industrial sector," Applied Energy, vol. 66, no. 2, pp. 105-111, Jun. 2000. [Online]. Available: http://linkinghub.elsevier.com/retrieve/pii/ S0306261999001257

[4] T. Logenthiran, D. Srinivasan, and T. Z. Shun, "Demand side management in smart grid using heuristic optimization," IEEE Transactions on Smart Grid, vol. 3, no. 3, pp. 1244-1252, 2012. [Online]. Available: http://ieeexplore.ieee.org/xpls/abs_all.jsp? arnumber $=6213581$

[5] L. Siebert and L. Ferreira, "Centralized and decentralized approaches to demand response using smart plugs," in $T \& D$ Conference and Exposition, Chicago, 2014, pp. 1-5. [Online]. Available: http:// ieeexplore.iee.. rg/xpls/abs_all.jsp?arnumber $=6863547$ 
[6] P. Palensky, F. Kupzog, A. A. Zaidi, and K. Zhou, "Modeling domestic housing loads for demand response," Nov. 2008 [Online]. Available: http://ieeexplore.ieee.org/lpdocs/epic03/wrapper. htm?arnumber $=4758392$

[7] K. Kok and B. Roossien, "Dynamic pricing by scalable energy management systemsField experiences and simulation results using PowerMatcher," in Power and Energy ..., no. July, 2012. [Online]. Available: http://ieeexplore.ieee.org/xpls/abs_all.jsp? arnumber $=6345058$

[8] S. Gottwalt, W. Ketter, C. Block, J. Collins, and C. Weinhardt, "Demand side management - A simulation of household behavior under variable prices," Energy Policy, vol. 39, no. 12, pp. 81638174, Dec. 2011. [Online]. Available: http://linkinghub.elsevier.com/ retrieve/pii/S0301421511008007

[9] G. T. Costanzo, G. Zhu, M. F. Anjos, and G. Savard, "A System Architecture for Autonomous Demand Side Load Management in Smart Buildings," Dec. 2012. [Online]. Available: http://ieeexplore. ieee. org/lpdocs/epic03/wrapper.htm?arnumber=6376273

[10] A. D. Peacock and E. H. Owens, "Assessing the potential of residential demand response systems to assist in the integration of local renewable energy generation," Energy Efficiency, vol. 7, no. 3, pp. 1-12, Dec. 2013. [Online]. Available: http://link.springer.com/10. 1007/s12053-013-9236-4

[11] Energieagentur Nordrhein-Westfalen, "Erhebung: Wo im Haushalt bleibt der Strom?" Apr. 2011

[12] H. Morsali and S. Shekarabi, "Smart plugs for building energy management systems," Smart Grids (ICSG), vol. 1, no. 1, pp. 2-6, 2012. [Online]. Available: http://ieeexplore.ieee.org/xpls/abs_all.jsp? arnumber $=6243554$

[13] L. Li, L. Xiang-long, C. Xiao, L. Ming, and L. Han-zhu, "The Utilization of Fuzzy Control in Energy Saving Control System of Water Source Heat Pump," in 2009 International Conference on Energy and Environment Technology. Ieee, 2009, pp. 471-474. [Online]. Available: http://ieeexplore.ieee.org/lpdocs/epic03/wrapper. htm?arnumber $=5366787$

[14] A. Arteconi, N. J. Hewitt, and F. Polonara, "Domestic demand-side management (DSM): Role of heat pumps and thermal energy storage (TES) systems," Applied Thermal Engineering, vol. 51, no. 1-2, pp. 155-165, Mar. 2013. [Online]. Available: http://linkinghub.elsevier. com/retrieve/pii/S1359431112006357

[15] D. Saker, P. J. Coker, M. Vahdati, S. Millward, and C. Carey, "Unlocking the demand response potential from domestic hot water tanks," in 4th Annual TSBE EngD Conference Proceedings, 2013. [Online]. Available: http://www.reading.ac.uk/web/FILES/tsbe/Saker_ TSBE_Conference_Paper_2013.pdf

[16] G. Strbac, "Demand side management: Benefits and challenges," Energy Policy, vol. 36, no. 12, pp. 4419-4426, 2008. [Online]. Available: http://linkinghub.elsevier.com/retrieve/pii/ S0301421508004606

[17] N. Yu and J. L. Yu, "Optimal TOU decision considering demand response model," in 2006 International Conference on Power System Technology, POWERCON2006, 2007, pp. 1-5. [Online]. Available: http://ieeexplore.ieee.org/xpls/abs_all.jsp?arnumber=4116286

[18] M. Albadi and E. El-Saadany, "A summary of demand response in electricity markets," Electric Power Systems Research, vol. 78, no. 11, pp. 1989-1996, Nov. 2008. [Online]. Available: http:// linkinghub.elsevier.com/retrieve/pii/S0378779608001272

[19] O. Franz and E. al., "Final Report E-Energy: E-DeMa," RWE Deutschland, Essen, Tech. Rep., 2013. [Online]. Available: http:// www.e-dema.de/datas/150 dpi E-DeMa_Abschlussbericht final.pdf

[20] S. Goelz and E. al., "Intelliekon. Nachhaltiger Energiekonsum von Haushalten durch intelligente Zaehler-, Kommunikationsund Tarifsysteme. Endbericht," Frauhofer Institute For Solar Energy Systems ISE, Freiburg, Tech. Rep., 2011. [Online]. Available: http://www.isoe.de/fileadmin/redaktion/Downloads/ Energieeffizienz/intelliekon-bericht-2011.pdf

[21] M. Agsten, "Abschlussbericht eTelligence," EWE AG, Oldenburg, Tech. Rep., 2012. [Online]. Available: http://www.etelligence.de/feldtest/file/ EWE102189EVEeTelligenceAbschlussberichtInhaltGBInternet_ sc.pdf

[22] A. Kiessling and E. al., "Final Report Modellstadt Mannheim," MVV Energie AG, Mannheim, Tech. Rep., 2013. [Online]. Available: http://www.modellstadt-mannheim.de/moma/web/media/ pdf/moma_Abschlussbericht.pdf

[23] S. Gyamfi, S. Krumdieck, and T. Urmee, "Residential peak electricity demand responseHighlights of some behavioural issues," Renewable and Sustainable Energy Reviews, vol. 25, pp. 71-77, 2013. [Online]. Available: http://linkinghub.elsevier.com/retrieve/pii/ S1364032113002578
[24] S. Higginson, E. McKenna, T. Hargreaves, J. Chilvers, and M. Thomson, "Diagramming social practice theory: An interdisciplinary experiment exploring practices as networks," Indoor and Built Environment, vol. 24, no. 7, pp. 950-969, 2015. [Online]. Available: http://ibe.sagepub.com/cgi/doi/10.1177/ 1420326X15603439

[25] S. Higginson, I. Richardson, and M. Thomson, "Energy use in the context of behaviour and practice: the interdisciplinary challenge in modelling flexible electricity demand," in Proc. Energy and People: Futures, Complexity and Challanges, no. September, Oxford UK, 2011.

[26] B. Stephen, X. Tang, P. R. Harvey, S. Galloway, and K. I. Jennett, "Incorporating Practice Theory in Sub-Profile Models for Short Term Aggregated Residential Load Forecasting," IEEE Transactions on Smart Grid, vol. PP, no. 99, pp. 1-8, 2015.

[27] A. K. David and Y. Z. Li, "Effect of inter-temporal factors on the real time pricing of electricity," IEEE Transactions on Power Systems, vol. 8, no. 1, pp. 44-52, 1993.

[28] D. S. Kirschen, G. Strbac, P. Cumperayot, and D. P. De Mendes, "Factoring the elasticity of demand in electricity prices," IEEE Transactions on Power Systems, vol. 15, no. 2, pp. 612-617, 2000.

[29] N. Venkatesan, J. Solanki, and S. K. Solanki, "Residential Demand Response model and impact on voltage profile and losses of an electric distribution network," 2012. [Online]. Available: http:// linkinghub.elsevier.com/retrieve/pii/S0306261911008798

[30] K. McKenna and A. Keane, "Discrete Elastic Residential Load Response under Variable Pricing Schemes," in 5th IEEE Innovative Smart Grid Technologies Europe, 2014, pp. 1-6.

[31] _ , "Residential Load Modeling of Price-Based Demand Response for Network Impact Studies," IEEE Transactions on Smart Grid, vol. in print, pp. 1-10, 2015.

[32] D. Fischer, A. Härtl, and B. Wille-Haussmann, "Model for electric load profiles with high time resolution for German households," Energy and Buildings, vol. 92, pp. 170-179, Apr. 2015. [Online]. Available: http://www.sciencedirect.com/science/article/pii/ S0378778815000845

[33] Eurostat, "Harmonized European Time Use Surveys," Brussels, 2000. [Online]. Available: https://www.h5.scb.se/tus/tus/

[34] B. Stephen, S. Galloway, and G. Burt, "Self-Learning Load Characteristic Models for Smart Appliances," IEEE Transactions on Smart Grid, vol. 5, no. 5, pp. 2432-2439, 2014.

[35] M. Rowe, T. Yunusov, S. Haben, W. Holderbaum, and B. Potter, "The Real-Time Optimisation of DNO Owned Storage Devices on the LV Network for Peak Reduction," Energies, vol. 7, no. 6, pp. 3537-3560, 2014. [Online]. Available: http://www.mdpi.com/ 1996-1073/7/6/3537/

[36] P. Palensky and D. Dietrich, "Demand Side Management: Demand Response, Intelligent Energy Systems, and Smart Loads," IEEE Transactions on Industrial Informatics, vol. 7, no. 3, pp. 381-388, Aug. 2011. [Online]. Available: http://ieeexplore.ieee.org/lpdocs/ epic03/wrapper.htm?arnumber $=5930335$ 